\title{
Health-Promoting Lifestyle Behaviours Among Primary Healthcare Professional Nurses in Eastern Cape Province, South Africa
}

\author{
Sizeka Monakali ${ }^{1}$, Daniel Ter Goon ${ }^{1}$, Eunice Seekoe ${ }^{1} \&$ Eyitayo Omolara Owolabi ${ }^{1}$ \\ ${ }^{1}$ Department of Nursing Science, Faculty of Health Sciences, University of Fort Hare, East London, South Africa \\ Correspondence: Eyitayo Omolara Owolabi, Department of Nursing Science, Faculty of Health Sciences, \\ University of Fort Hare, East London, 5200 South Africa. Tel: 277-30-719-622. E-mail: \\ owolabiomolara101@gmail.com
}

Received: August 16, 2018 Accepted: December 6, 2018 Online Published: December 18, 2018

doi:10.5539/gjhs.v11n1p92 URL: https://doi.org/10.5539/gjhs.v11n1p92

\begin{abstract}
Nurses play significant roles in health promotion and health education about healthy lifestyle practices and are considered role models of healthy lifestyle behaviours. It is unclear if their knowledge of healthy lifestyle choices translate to practice. This study assessed the lifestyle behaviours of primary healthcare professional nurses in the Eastern Cape Province, South Africa. This descriptive, cross-sectional study involved 203 purposively selected primary healthcare nurses in Eastern Cape Province, South Africa. We utilised the WHO STEPwise questionnaire to assess the lifestyle behaviour (smoking, alcohol use and physical activity) of the nurses. Descriptive and inferential statistics were carried out at a significance level of $p<0.05$. The participants' mean age was 45.17 (Standard Deviation \pm 11.26 ) years. Of all the participants, $27 \%$ had ever taken alcohol, and $18 \%$ currently use alcohol. Only $8 \%$ had ever smoked and of these, $3 \%$ currently smoke. Of all the participants, $33 \%$ do not engage in physical activities, and only $29 \%$ of them met the WHO recommendation for being active. Most of them were aware of the benefits of physical activities. Majority of the participants cited lack of time (74\%) and lack of commitment $(63 \%)$ as barriers to physical activity and few of them cited health challenges (3.9\%). Among the primary health care professional nurses in this setting, we found a high prevalence of alcohol use and low prevalence of smoking and physical activity among primary health care nurses in this setting. There is a need to implement effective workplace strategies and wellness programmes that will foster healthy lifestyle practices among the nurses.
\end{abstract}

Keywords: nurses, lifestyle behaviour, primary healthcare, Eastern Cape, South Africa

\section{List of abbreviations}

NCDS: Non-communicable diseases

PHC: Primary Health Care

WHO: World Health Organisation

SD: Standard Deviation

EC: Eastern Cape

BCMM: Buffalo City Metropolitan Municipality

\section{Introduction}

Non-communicable diseases (NCDs) are significant public health, developmental, social and economic concerns, and are the foremost causes of morbidity and mortality worldwide (WHO, 2017). Various modifiable factors like smoking inadequate physical activity, poor dietary practices, harmful alcohol use, overweight and obesity are majorly responsible for the increase in the burden of NCDs $\backslash$ (WHO, 2017). Irrespective of the gruesome burden associated with non-communicable diseases, they are largely preventable through the prevention of the associated risk factors.

While the focus of policy makers and researchers regarding the burden of non-communicable diseases has been on the general population, little attention is paid to the burden among health care workers. This might be as a result of the general belief that healthcare workers are more knowledgeable about NCDs and associated lifestyle behaviours (Blake \& Harrison, 2013; Skaal \& Pengpid, 2011). However, their knowledge might not necessarily translate to 
practice as high prevalence of unhealthy behaviours, overweight and obesity has been reported among nurses (Blake, Mo, Lee, \& Batt, 2012; Blake, Goon et al., 2013; Malik, Blake, \& Batt, 2011; Mo, Blake, \& Batt, 2011; Phiri, Draper, Lambert, \& Kolbe-Alexander, 2014; Skaal \& Pengpid, 2011; Stanulewicz, \& Griffiths, 2017).

Worryingly, this occupational group are at a very high risk as some of the non-communicable disease have been linked to working conditions such as long duration of work, high job expectations and rotational shifts which characterise the healthcare system (De Bacquer et al., 2009; LdCÃo, 2010; Morikawa et al., 2008; Zhao \& Turner, 2008; Zhao et al., 2011). These factors put the nurses under stress and afford them little opportunities to engage in activities that promote health such as physical and recreational activities (Blake \& Harrison, 2013; Blake et al., 2011; Melnyk, Hrabe, Szalacha, 2013; Naidoo \& Coopoo, 2007). Nurses are reported to engage in ineffective coping mechanisms and unhealthy practices such as alcohol and substance abuse, smoking, and consumption of unhealthy diet which further increase their risk (Malik, Blake, Batt, 2011; Hensel, 2011).

Several studies conducted among nurses in various countries have highlighted a high burden of NCDs, overweight, obesity and unhealthy lifestyle behaviours such as alcohol use, smoking, physical inactivity and poor dietary practices among them (Blake \& Harrison, 2013; Kurnat-Thoma, EL-Banna, Oakcrum, \& Tyroler, 2017; Miller, Alpert \& Cross, 2008; Naidoo \& Coopoo, 2007; Phiri et al., 2014; Skaal \& Pengpid, 2011). Generally, high burden of obesity, non-communicable diseases such as obesity (Adeniyi, Longo-Mbenza, \& Goon, 2015; Owolabi, Goon, Adeniyi, Adedokun, \& Seekoe, 2017a), diabetes (Adeniyi, Yogeswaren, Lonog-Mbenza, Goon, \& Ajayi, 2016; Owolabi, Goon, Adeniyi, \& Seekoe, 2016), hypertension (Day et al., 2015; Owolabi, Goon, Adeniyi, \& Seekoe, 2016; Peer, Steyn, Lombard, Gwebushe, \& Levitt, 2013) and their associated factors have been documented among South African adults, including nurses (Goon et al., 2013; Naidoo \& Coopoo, 2007; Skaal \& Pengpid, 2011; Van den Berg, Okeyo, Danhausser, \& Mariette, 2012).

Health promotion and preventative measures, both formal and informal, are considered core components of nursing care (Blake, Malik, Mo, Pisano, 2011; Miller, Alpert, \& Cross, 2008). Unhealthy lifestyle behaviours among nurses and other health workers have a two-fold impact; aside the detrimental effect on the health of the nurses, it could also impede the reception of lifestyle modification counsels given to the patients and the community by such nurses. Nurses' direct contact with patients, families and communities offer them the opportunity to influence changes in health behaviours among the general population (Blaber, 2005). These roles could be threatened by a high burden of NCDs among nurses (Blake et al., 2012; Bogossian et al., 2012). High burden of NCDs and unhealthy lifestyle practices among nurses could constitute significant threat to the individual and the healthcare system and adversely affect practice (Blake et al., 2012; Melynk, Hrabe, \& Szalacha, 2013; South African Department of Health, 2012). Also, nurses with poor health behaviour may have a lesser likelihood of offering advice on the benefits of healthy lifestyle behaviours (Seir \& Osler, 2002; South African Department of Health, 2012). Likewise, it may be unrealistic to expect patients and communities to be committed to plans on living a healthy lifestyle when the health educator advocating such behaviours does not model it (Miller, Alpert, \& Cross, 2008). Finally, high burden of NCDs and unhealthy lifestyle practices among nurses and other health workers could impact on the healthcare workforce, in terms of reduced productivity and increased absenteeism at work (Bogossian et al., 2012; Skaal \& Pengpid, 2011).

Although some studies have evaluated the burden of non-communicable disease, overweight and obesity among nurses and nurses in training in South Africa (Goon et al., 2013; Naidoo \& Coopoo, 2007; Skaal \& Pengpid, 2011; Van den Berg, Okeyo, Danhausser, \& Mariette, 2012), only a few assessed their lifestyle behaviours such as tobacco use, alcohol use, dietary practices as well as engagement in physical activities, which are major contributors to the growing burden of NCDs. The few studies that assessed their lifestyle behaviours focused on their dietary and physical activity patterns (Phiri et al., 2014; Van den Berg et al., 2012), neglecting two other important factors; smoking and alcohol use. These previous studies have both documented poor dietary practices and physical inactivity among nurses in South Africa. Also, such previous studies considered only nurses in secondary and tertiary level of healthcare, neglecting nurses at the primary healthcare level who are mostly involved in primary healthcare which include health promotion and preventive activities. Therefore, the objective of this study is to assess the lifestyle behaviours (smoking, alcohol use, physical activities pattern) of primary health care professional nurses in an economically disadvantaged province of Eastern Cape, South Africa. In this setting, primary healthcare professional nurses are nurses who have undergone at least four years of formal training as a nurse, with an additional specialisation experience in primary health care/clinical health assessment and licensed to assess patients, diagnose and prescribe. The primary health health professional nurses are also the nurses who run the primary health care and community health care facilities. The findings of this study will help to determine how much the primary healthcare nurses in this setting model the lifestyle behaviours they advocate for. Also, such information is essential in designing appropriate workplace interventions targeted towards promotion 
of healthy lifestyle behaviour and reduction of the burden of NCDs among health workers.

\section{Methodology}

\subsection{Study Area and Design}

A quantitative approach with a descriptive, cross- sectional research design was used to screen for the prevalence of overweight and obesity among professional primary health care nurses, working across 41 primary healthcare (PHC) facilities in Eastern Cape. The Eastern Cape forms part of the nine provinces of South Africa. Its capital is in Bisho. Eastern Cape Province was created in 1994 from the Xhosa homelands of Transkei and Ciskei along with the eastern segment of the Cape Province. It forms a base for the Xhosa people. The province has two metropolitan municipalities; Buffalo City Metropolitan Municipality (BCMM), Nelson Mandela Metropolitan Municipality and six districts; Amathole, Joe Gqabi, O.R Tambo, Sarah Bartman, Chris Hani and Alfred Ndzo.

\subsection{Sampling}

A purposive sampling was used to select primary health care nurses from four randomly selected districts. First, four of the six districts and two metropoles of the Eastern Cape Province were randomly selected using simple randomization, namely, Buffalo City Metropolitan Municipality, O.R Tambo, Chris Hani, and Sarah Baartman Districts. The randomization was done by assigning numbers to the eight districts and these numbers were wrapped up by someone not involved in the study. After this, the researcher blindly selected four. From the four randomly selected districts/municipalities, 41 primary health care centres were then selected using convenience sampling.

There are approximately 880 nurses in the selected districts $(\mathrm{OR}$ Tambo $=250$, Chris Hani $=230$, Sarah Baartman $=100$, and $\mathrm{BCMM}=300)$. At a confidence level of $95 \%$, a sample size of 268 nurses would have been required. However, only 203 (76\%) primary health professional nurses (PNs) were accessible and included in the study due to shortage of staff in PHC facilities, especially in rural districts like OR Tambo. The study was conducted between February and May, 2017.

\subsection{Eligibility Criteria}

Participants were included in the study if they were PHC professional nurses, aged 18 years and above, practicing in the PHC facilities, on duty and willing to participate in the study during the day of data collection. Exclusion criteria included pregnancy or any form of debilitation in such a manner that affects taking anthropometric measurement.

\subsection{Data Collection Instrument}

The modified WHO STEPwise questionnaire with three major sections; demographic data, behavioral variables and anthropometric data was used for data collection. In order to determine suitability of the instrument, a pilot study was conducted among 20 PHC professional nurses at Mnquma sub district, under Amathole district.

\subsection{Data Collection}

Face-to-face interview was used to obtain demographic and behavioural characteristics to ensure completeness of information. Sex, age, marital status, level of education, employment status, duration of practice and average monthly income were the demographic variables. Lifetime and current alcohol use was assessed by self-reporting of alcohol use using the questions; "have you ever taken any alcoholic drink?", "do you currently take alcohol?" "'In the past 30 days, have you taken any alcoholic drink?" "'In the past 30 days, how often did you take alcohol?", How many standard bottles of alcohol (containing $10 \mathrm{~g}$ of ethanol) do you take at a sitting?".

Regarding tobacco use, lifetime and current tobacco use were also assessed. The questions asked were: "have you ever smoked or use any tobacco products?" "In the last 30 days, have you used any tobacco product?" "What type of tobacco product do you use?" and "how many sticks do you use on an average daily?".

Physical activity pattern was assessed with the following questions: Do you engage in any form of physical activity? How many days do you engage in moderate/vigorous activities? How many minutes do you spend on each day? The overall activity pattern was accessed using the WHO recommendation for physical activity; 150 minutes per week for moderate-intensity activities or 70 minutes per week of vigorous-intensity activity per week. Participants were categorised as either active or not active based on the Yes/No answer. Those who reported engaging in activities were then further categorised into those who met the recommended minutes and those who does not. The perceived benefits of physical activity and barriers were assessed. Data collection took place between February and May 2017. 


\subsection{Ethical Consideration}

The ethical clearance was obtained from the Research and Ethics Committee of the University of Hare (Reference number; EC-2015RP10-426) which followed the Helsinki Declaration. Permission to carry out the study was obtained from the Eastern Cape Department of Health $(\mathrm{ECDoH})$, district managers, sub district managers and facility managers. We obtained written informed consent to participate in this study from all participants. We ensured anonymity and confidentiality throughout the study.

\subsection{Data Analysis}

Data were analysed using SPSS version 23 for windows (SPSS Inc., Chicago, IL, USA). We expressed data as mean values \pm standard deviations $(\mathrm{SD})$ for continuous variables. Counts (frequency $=\mathrm{n}$ ) and proportions $(\%)$ were reported for categorical variables. Percentages were compared using chi-square test. Descriptive and inferential statistics were used for determining the prevalence and determinants of overweight and obesity among the study participants. All the variables which were significantly associated in the bivariate analysis were included in the logistic regression model analysis. An unadjusted regression analysis was done by computing models for each of the independent variables while the adjusted regression analysis included a model containing all the independent variables which was then adjusted for confounder, smoking. A p-value of $<0.05$ was considered statistically significant.

\section{Results}

The demographic characteristics of participants are shown in Table 1. The mean age of the study participants was 45.17 ( $\mathrm{SD} \pm 11.26$ ) years.The average duration of practice was 15.98 ( $\mathrm{SD} \pm 11.07$ ) years. Almost half of the participants were married (49.8\%) and majority (65\%) have a diploma certificate in nursing earning more than R15, $000(60.6 \%)$.

Table 1. Socio-demographic characteristics of participants by gender

\begin{tabular}{llll}
\hline Variables & All & Female & Male \\
\hline Age (years) & & & \\
21 to 30 & $26(12.8)$ & $19(10.6)$ & $7(29.2)$ \\
31 to 40 & $50(24.6)$ & $41(22.9)$ & $9(37.5)$ \\
41 to 50 & $42(20.7)$ & $39(21.8)$ & $3(12.5)$ \\
51 to 60 & $74(36.5)$ & $69(38.5)$ & $5(20.8)$ \\
61 to 70 & $11(5.4)$ & $11(6.1)$ & $0(0.0)$ \\
Marital Status & & & \\
Single & $83(40.9)$ & $71(39.7)$ & $12(50.0)$ \\
Married & $101(49.8)$ & $90(50.3)$ & $11(45.8)$ \\
Divorced & $9(4.4)$ & $9(5.0)$ & $0(0.0)$ \\
Separated & $1(0.5)$ & $1(0.6)$ & $0(0.0)$ \\
Widow/Widower & $9(4.4)$ & $8(4.5)$ & $1(4.2)$ \\
Number of Children & & & \\
1 & $37(20.4)$ & $33(20.4)$ & $4(21.1)$ \\
2 & $61(33.7)$ & $58(35.8)$ & $3(15.8)$ \\
3 & $58(32.0)$ & $49(30.2)$ & $9(47.4)$ \\
4 & $18(9.9)$ & $16(9.9)$ & $2(10.5)$ \\
5 & $5(2.8)$ & $5(3.1)$ & $0(0.0)$ \\
6 & $1(0.6)$ & $1(0.6)$ & $0(0.0)$ \\
7 & $1(0.6)$ & $0(0.0)$ & $1(5.3)$ \\
\hline
\end{tabular}




\begin{tabular}{llll}
\hline Level of Education & & & \\
Diploma (Three-year nursing programme) & $132(65.0)$ & $117(65.4)$ & $15(62.5)$ \\
Degree & $67(33.0)$ & $58(32.4)$ & $9(37.5)$ \\
Post-graduate Diploma & $3(1.5)$ & $3(1.7)$ & $0(0.0)$ \\
Masters & $1(0.5)$ & $1(0.6)$ & $0(0.0)$ \\
Race & & & \\
Black & $195(96.1)$ & $171(95.5)$ & $24(100.0)$ \\
Coloured & $8(3.9)$ & $8(4.5)$ & $0(0.0)$ \\
Duration of Practice & & & \\
1 to 10 years & $72(40.7)$ & $59(38.1)$ & $13(59.1)$ \\
11 to 20 years & $41(23.2)$ & $37(23.9)$ & $4(18.2)$ \\
21 to 30 years & $44(24.9)$ & $41(26.5)$ & $3(13.6)$ \\
31 and above & $20(11.3)$ & $18(11.6)$ & $2(9.1)$ \\
Income & & & \\
10000 to 15000 & $65(39.4)$ & $55(38.5)$ & $10(45.5)$ \\
Above 15000 & $100(60.6)$ & $88(61.5)$ & $12(54.5)$
\end{tabular}

Of all the participants, $27 \%$ had ever taken alcohol, while $67 \%$ of those who reported ever consuming alcohol (18 percent of the entire participants) still currently consume it.

\subsection{Binge Drinking}

The mean number of standard bottles of alcohol taken by the nurses was 4.31 bottles ( $\mathrm{SD} \pm 3.2$ ), with a higher mean among males (5.62) compared to females (3.55).

Of all the socio-demographic characteristics, only male sex, never married, younger age were significantly associated with ever using alcohol among the study participants.

Table 2. Association of lifetime alcohol consumption with socio-demographic characteristics

\begin{tabular}{llll}
\hline Variables & Consume Alcohol & Do Not Consume Alcohol & P-Value \\
\hline Gender & $18(75.0)$ & $6(25.0)$ & $<0.001$ \\
Male & $36(20.1)$ & $143(79.9)$ & \\
Female & & & \\
Marital status & $29(34.9)$ & $54(65.1)$ & 0.019 \\
Never married & $25(20.8)$ & $95(63.8)$ & \\
Ever married & & & $<0.001$ \\
Age (years) & $19(73.1)$ & $7(26.9)$ & \\
21 to 30 & $18(36.0)$ & $32(64.0)$ & \\
31 to 40 & $10(23.8)$ & $32(78.2)$ & \\
41 to 50 & $7(9.5)$ & $67(90.5)$ & \\
51 to 60 & $0(0.0)$ & $11(100.0)$ & \\
61 to 70 & & & \\
Income & $23(35.4)$ & $76(64.6)$ & \\
10000 to 15000 & $24(24.0)$ & & \\
Above 15000 & & & \\
\hline
\end{tabular}




\subsection{Smoking Behaviour Among Nurses}

Of the 203 participants, only $8 \%$ had ever smoked and of these, $47 \%$ ( 3 percent of the entire participants) currently smoke.

\subsection{Physical Activity Pattern}

Of all the participants, $33 \%$ do not engage in physical activities, and of the remaining $67 \%$, only $29 \%$ of them met the WHO recommendation for being active.

Of all the participants, $33 \%$ do not engage in physical activities, and of the remaining $67 \%$, only $29 \%$ of them met the WHO recommendation for being active. Most of them were aware of the benefits of physical activities concerning weight loss (93.1\%), better sleep and alertness (95.5\%), and for better heart functions $(96.5 \%)$. The majority of the participants cited lack of time $(74.0 \%)$ and lack of commitment $(63.3 \%)$ as barriers to physical activity and few of them cited health challenges (3.9\%) (Figure 1).

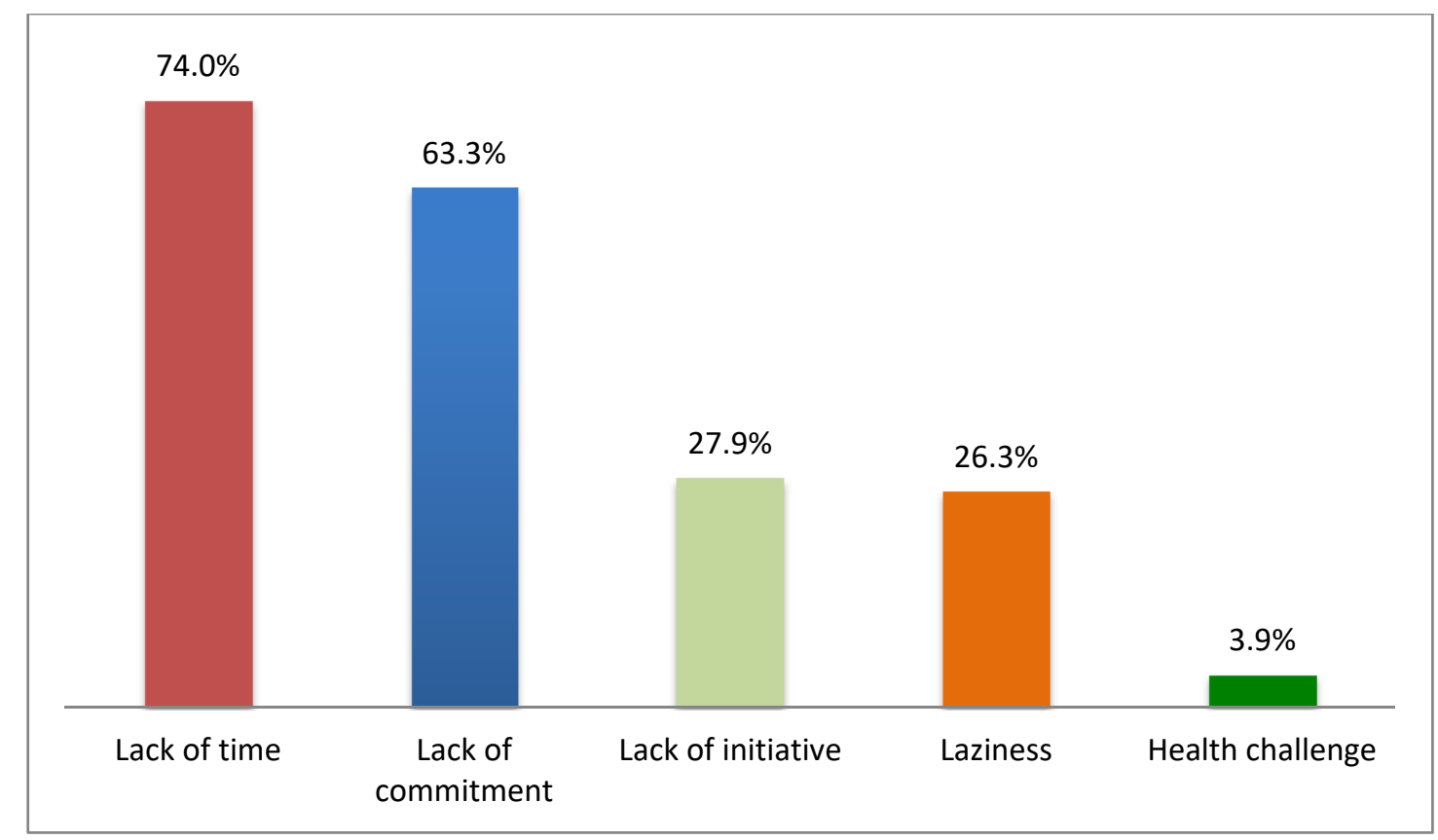

Figure 1. Barriers to physical activity participation

\section{Discussion}

This present study examines the lifestyle behaviours (smoking, alcohol use, and physical activity) of primary healthcare professional nurses in Eastern Cape, South Africa. These factors among others have been identified as the underlying factors responsible for as much as $80 \%$ of the burden of non-communicable diseases (WHO, 2011). Of the 203 nurses involved in this study, only eight percent had ever smoked or used any tobacco product and only three percent of the nurses currently smoke. This proportion of nurses who had ever smoked and are current smokers is quite lower than the reported rate among nurses in Turkey (40\%) (Adamek et al., 2012) and 45\% (Sezer, Guler, \& Sezer, 2007), Japan (18.6\%) (Ohida, Osaki, Kobayashi, Sekiyama, \& Minowa, 1999) and the United States (8\%) (Sarna, Bialous, Sinha, Yang, \& Wewers, 2010) When compared to the general population, the prevalence reported in this study is lower than the $15 \%$ reported among adults in the same setting (Owolabi et al., 2017c). This is commendable as this shows that the nurses in this setting detest smoking and this might have influence on the health education they offer to patients concerning smoking. Also, a decline in the rate of smoking among nurses has been shown to be accompanied by a fall in the prevalence of smoking in the general population (Sarna, Bialous, Sinha, Yang, \& Wewers, 2010). Various workplace policies such as prohibition of smoking at workplace, especially at the healthcare settings might have contributed to this. However, there is still a need to further encourage the nurses and assist those who still smoke to quit smoking.

Primary healthcare professional (PHC) nurses play a significant role in health educating patients and communities on harmful alcohol use; however their disposition to alcohol use will significantly influence this role. Twenty 
seven percent of the nurses in this study had ever consumed alcohol and only $18 \%$ currently consume alcohol. Comparison of alcohol consumption among nurses in South Africa is fraught with difficulty as scant data exist. The prevalence of ever consuming alcohol among these study participants is lower than the reported prevalence among Kenyan nurses (35.8\%) (Mokaya et al., 2016). It is however higher than the prevalence reported among nurses in Norway, $0.3 \%$ (Edvardsen et al., 2014). The prevalence in this study is comparable to the reported prevalence (22\%) among healthcare professionals, including nurses in another province of South Africa (Okeke, Ross, Esterhuizen, \& Van Wyk, 2012). Also, it is comparable to the reported prevalence among doctors in Nigeria, 30.3\% (Obadeji, Oluwole, Dada, Adegoke, 2015). This evidence further affirms the fact that health workers, including the nurses also participate in unhealthy lifestyle behaviours such as harmful alcohol use, and nurses in this settings are not exempted. Their rate of alcohol consumption is slightly lower than the reported prevalence (32\%) among the general population in the same setting (Owolabi et al., 2017d). Considering the important role of nurses, particularly the primary healthcare professional nurses, in the advocacy for healthy lifestyle behaviors, alcohol use among them might impede this role. Alcohol use among nurses might affect the quality of care rendered or even their sense of clinical judgement, although this association was not established in this study. Alcohol use among nurses might constitute a major threat for the healthcare system and even further increase the challenges of high litigations faced by the South African healthcare system. In addition, given that harmful alcohol use predisposes to chronic illnesses, the health of these nurses might be compromised; and this might affect the healthcare workforce. In addition, the mean number of standard alcohol taken by the nurses in this study was 4.31 bottles with a higher mean among men compared to women. These recorded mean values are synonymous to the range for binge drinking (four or more standard drinks among women or five or more standard drinks among men at an occasion). This shows that those who consume alcohol among this cohort engage in binge drinking, a form of hazardous drinking. This will not only result in poor health outcomes such as chronic diseases and injuries but can also affect the quality of life of these nurses (CDC, 2017). This might also affect their work performance and the care rendered to the patients and the communities, which may see them as role models.

Male nurses had a higher prevalence of lifetime alcohol use. This is not surprising as similar findings have been documented among other populations (Owolabi et al., 2017d; Reddy et al., 2010). Alcohol use appears more socially acceptable among men compared to women (Bratberg, 2016). Also, as observed in this study, the use of alcohol decreases with advancing age. This is similar to other studies (Owolabi et al., 2017d; Reddy et al., 2010). As age advances, maturity and more responsibilities sets in. Even in the absence of those, disease conditions might also begin to develop. These could collectively contribute to older adults' decision to either reduce alcohol consumption or abstain from it. This might also be the underlying reason behind the higher prevalence found among the never married participants as they constitute those in the younger age groups. There was no significant difference between various income groups and alcohol. All the participants have a good purchasing power for alcohol as they all earn more than R15000 per month. Aside this, alcohol appears to be relatively cheap and easily accessible in this setting. Thus, irrespective of income, everyone have access to alcohol and can easily purchase it.

Considering the significant health implications of physical inactivity, this study assessed the physical activity pattern of the nurses in this setting. Of all the participants, 33\% do not engage in physical activities, and of the remaining $67 \%$, only $29 \%$ of them met the WHO recommendation for being active. Overall, as many as $71 \%$ were either not active or insufficiently active. When compared to studies outside South Africa, the observed prevalence of physical inactivity in this study is higher than the documented prevalence of physical inactivity among nurses in the United Kingdom (48\%) (Blake, Stanulewics, McGill, 2017), United States (68\%) (Fitzgerald, 2015) and among nurses in South Africa (Phiri et al., 2014), in which all the nurses were reported to have met the recommended physical activity level. This shows that the nurses in this setting are not modelling the healthy lifestyle in terms of physical activity they advocate for, and as a result of this, they might be at a risk of developing non-communicable diseases. Nurses constitute a larger percentage of the healthcare workforce; as such a high burden of non-communicable diseases among them might paralyse the healthcare system. Even though lack of physical activity might not physically be observable, however, one of its side effects of becoming obese is apparent. As a result of this, patients with similar lifestyle behaviour might find it difficult adhering to advice received from nurses who do not also comply.

When asked about the perceived benefits and barriers, majority of the nurses were aware of the benefits of physical activity. Some highlighted benefits include weight loss (93.1\%), better sleep (95.5\%) and alertness (96.5\%). The listed benefits of physical activity is synonymous to the documented benefits; reduction of the risk of developing heart diseases, diabetes, cancer, injury, better mental health (CDC, 2017; NHLBI, 2016). However, this shows that the nurses' knowledge about the benefits of physical activity do not translate into practice. In spite of being knowledgeable about the various benefits of physical activity, they still do not feel obliged to engage in such 
activities. This poor attitude towards physical activity among nurses in this setting warrants intervention. When asked about the perceived barriers to engaging in physical activities, the nurses highlighted lack of time (74.0\%), lack of commitment (63.3\%) as the major barriers. This is synonymous to the reported barriers among nurses in the UK (Blake, Stanulewicz, \& McGill, 2017), and reported evidence in a review study (Trost, Owen, Bauman, Sallis, and Brown (2002). This is worrying as the nurses are knowledgeable and yet are not committed to participate in physical activity because of lack of sufficient time. There is a need to create a work environment which will facilitate exercise at work and implement physical activity promoting initiatives among the nurses. Also, more emphasis should be laid on observing the wellness days at work and physical activity participation should be incorporated in such days. This could motivate the nurses to be active and will promote their health and reduce their risk for developing NCDs, as shown in some interventional studies assessing the effect of physical activity on the health of nurses (Blaber, 2005; Gartshore \& Blake, 2014).

\subsection{Limitations}

The cross-sectional approach and self-reporting of the lifestyle behaviours are obvious limitations of this study. Also, the findings of this study might not be generalizable to the entire South African nurses. However, this study is the first to assess the lifestyle behaviours among nurses in the Eastern Cape Province, South Africa. The findings of this present study provides a snapshot of the healthy lifestyle behaviours of nurses in the study setting.

\section{Conclusion}

The study documented high prevalence of alcohol consumption; commendably, low prevalence of smoking, but low physical activity among PHC professional nurses in Eastern Cape, South Africa. There is a need for the implementation of workplace wellness programmes that will foster healthy lifestyle behaviours among nurses in this setting.

\section{Funding}

SM received Doctoral study grant from the Health and Welfare Sector Education and Training Authority, South Africa, for the implementation of the project.

\section{Authors' Contributions}

SM, DTG and ES conceptualised and designed the study. EOO engaged in data collection, data analysis and drafting of the paper. All authors read and approved the final manuscript.

\section{Acknowledgements}

The authors are grateful to the management and nursing staff of the three health facilities for their support towards the successful implementation of the project.

\section{Availability of Data}

Data from this study will be made available on request.

\section{Competing Interests Statement}

The authors declare no conflict of interest.

\section{References}

Adamek, R., Stoczyńska, J., Maksymiuk, T., Zysnarska, M., Gromadecka-Sutkiewicz, M., Kara, I., \& Kalupa, W. (2012). Prevalence of tobacco smoking among nurses and the awareness of harmfulness of smoking habit. Przegl Lek., 69(10), 969-72. https://doi.org/10.20883/jms.2016.3

Adeniyi, O. V., Longo-Mbenza, B., \& Goon, D. T. (2015). Female sex, poverty and globalization as determinants of obesity among rural South African type 2 diabetics : a cross-sectional study. BMC Public Health, 15, 298. https://doi.org/10.1186/s12889-015-1622-8

Adeniyi, O. V., Yogeswaran, P., Longo-Mbenza, B., Goon, D. T., \& Ajayi, A. I. (2016). Cross- sectional study of patients with type 2 diabetes in OR Tambo district, South Africa. BMJ Open, 6, e010875. https://doi.org/10.1080/20786190.2017.1340251

Blaber, A. (2005). Exercise: who needs it? British Journal of Nursing, 14(18), 973-5. https://doi.org/10.12968/bjon.2005.14.18.19884

Blake, H., \& Harrison, C. (2013). Health behaviours and attitudes towards being role models. British Journal of Nursing, 22, 86-94. https://doi.org/10.12968/bjon.2013.22.2.86

Blake, H., Malik, S., Mo, P. K., \& Pisano, C. (2011). 'Do as say, but not as I do': are next generation nurses role 
models for health? Perspectives of Public Health, 131(5), 231- 9. https://doi.org/10.1177/1757913911402547

Blake, H., Mo, P.K., Lee, S., \& Batt, M. E. (2012). Health in the NHS: lifestyle behaviours of hospital employees. Perspectives of Public Health, 132(5), 213-5. https://doi.org/10.1177/1757913912457309

Blake, H., Stanulewicz, N., \& Griffiths, K. (2017). Healthy Lifestyle Behaviors and Health Promotion Attitudes in Preregistered Nurses: A Questionnaire Study. Journal of Nursing Education, 56(2), 94-103. https://doi.org/10.3928/01484834-20170123-06

Blake, H., Stanulewicz, N., \& McGill, F. (2017). Predictors of physical activity and barriers to exercise in nursing and medical students. Journal of Advanced Nursing, 73(4), 917-929. https://doi.org/10.1111/jan.13181

Bogossian, F. E., Hepworth, J., Leong, G. M., Flaws, D. F., Gibbons, K. S., Benefer C. A., ...\& Turner, C. T. (2012). A cross-sectional analysis of patterns of obesity in a cohort of working nurses and midwives in Australia, New Zealand, and the United Kingdom. Nursing Studies, 49(6), 727-738. https://doi.org/10.1016/j.ijnurstu.2012.01.003

Bratberg, G. T., Wilsnack, S. C., Wilsnack, R., Haugland, S. H., Krokstad, S, \& Sund, E. R. (2016). Gender differences and gender convergence in alcohol use over the past three decades (1984-2008), The HUNT Study, Norway. BMC Public Health, 16, 723-729. https://doi.org/10.1186/s12889-016-3384-3

Centre for Disease Prevention and Control. (2017). Physical activity and health. Retrieved from: https://www.cdc.gov/physicalactivity/basics/pa-health/index.htm.

Day, C., Groenewald, P., Laubscher, R., Chaudry, S., Van Schaik, N., \& Bradshaw. D. (2014). Monitoring of non-communicable diseases such as hypertension in South Africa: challenges for the post-2015 global development agenda. South African Medical Journal, 104, 680. https://doi.org/10.7196/SAMJ.7868

De Bacquer, D., Van Risseghem, M., Clays, E., Kittel, F., De Backer. G., \& Braeckman, L. (2009). Rotating shift work and the metabolic syndrome: a prospective study. International Journal of Epidemiology, 38, 848-854. https://doi.org/10.1093/ije/dyn360

Department of Health. (2012). NHS Health and Well-being Review: Interim report. 2009. Retrieved from: http://tinyurl.com/a6tamjj.

Edvardsen, H. M. E, Karinen, R., Moan, I. S., Oeistad, E. L, Christophersen, A. S., \& Gjere, F. (2014). Use of alcohol and drugs among health professionals in Norway: a study using data from questionnaires and samples of oral fluid. Journal of Occupational Medicine Toxicology, 9(8), 1-10. https://doi.org/10.1186/1745-6673-9-8

FitzGerald, L.Z. (2015). Categorization and determinants of physical activity among nursing students. Journal of Nursing Education and Practice, 5(5), 10-20. https://doi.org/10.5430/jnep.v5n5p10

Gartshore, E., \& Blake, H. (2014). 'Workplace Wellness': online Learning Package University of Nottingham, Nottingham. 2014. https://doi.org/10.1016/j.nepr.2016.07.001

Goon, D. T., Maputle, M. S., Olukoga, A., Lebese, R., Khoza, L. B., \& Ayanwu, F. C. (2013). Overweight, obesity and underweight in nurses in Vhembe and Capricorn districts, Limpopo. South African Journal of Clinical Nutrition, 26(3), 147-149. https://doi.org/10.1080/16070658.2013.11734459

Hensel, D. (2011). Relationships among nurses' professional self-concept, health, and lifestyles. West Africa Journal of Nursing Research, 33(1), 45-62. https://doi.org/10.1177/0193945910373754

Kurnat-Thoma, E., El-Banna, M., Oakcrum. M., \& Tyroler, J. (2017) Nurses' health promoting lifestyle behaviors in a community hospital. Health Advance, 35, 77-81. https://doi.org/10.1016/j.apnr.2017.02.012

LdCÃo, A., Jornada, M. N., Ramalho, L., \& Hidalgo, M. P. L. (2010). Correlation of shift work and waist circumference, body mass index, chronotype and depressive symptoms. Arq Brasil Endocrinolology and Metabololism, 54, 652-656. https://doi.org/10.1590/s0004- 27302010000700010

Malik, S., Blake, H., \& Batt, M. E. (2011). How healthy are our nurses? New and registered nurses compared. British Journal of Nursing, 20(8), 489-96. https://doi.org/10.12968/bjon.2011.20.8.489

McDowell, N., McKenna, J. \& Naylor, P. (1997). Factors that influence practice nurses to promote physical activity. British Journal of Sport Medicine, 31(4), 308-13. https://doi.org/10.1136/bjsm.31.4.308

Melnyk, B., Hrabe, D., \& Szalacha, L. (2013). Relationships among work stress, job satisfaction, mental health, and healthy lifestyle behaviors in new graduate nurses attending the nurse athlete program. Nursing Administration Quarterly, 37(4), 278-285. https://doi.org/10.1097/NAQ.0b013e3182a2f963 
Miller, S. K., Alpert, P. T., \& Cross, C. L. (2008). Overweight and obesity in nurses, advanced practice nurses, and nurse educators. Journal of American Academy of Nurse Practitioners, 20(5), 259-65. https://doi.org/10.1111/j.1745-7599.2008.00319.x

Mo P. K. H., Blake, H., \& Batt, M. E. (2011). Getting healthcare staff more active: the mediating role of self-efficacy. Br J Health Psychol, 16(4), 690-706. https://doi.org/10.1111/j.2044-8287.2010.02007.x

Mokaya, A. G., Mutiso, V., Musau, A., Tele, A., Kombe, Y., \& Ng'ang'a, Z. (2016). Substance use among a sample of healthcare workers in Kenya: A cross-sectional study. Journal of Psychology and Drugs, 48(4), 310-319. https://doi.org/10.1080/02791072.2016.1211352

Morikawa, Y., Miura, K., Sasaki, S., Yoshita, K., Yoneyama, S., Sakurai, M., ... \& Higashiyama M. (2008). Evaluation of the effects of shift work on nutrient intake: a cross-sectional study. Journal of Occupational Health, 50, 270-278. https://doi.org/10.1539/joh.L7116

Naidoo, R., \& Coopoo, Y. (2007). The health and fitness profiles of nurses in KwaZulu-Natal. Curationis, 30, 66-73. https://doi.org/10.4102/curationis.v30i2.1076

National Heart, Lung and Blood Institute. (2016). Benefits of physical activity. Retrieved from: https://www.nhlbi.nih.gov/health/health-topics/topics/phys/benefits. 2016.

Obadeji, A., Oluwole, L. O., Dada, M. U., \& Adegoke, B. O. (2015). Hazardous alcohol use among doctors in a Tertiary Health centre. Indian Psychiatry Journal, 24(1), 59-63. https://doi.org/10.4103/0972-6748.160935

Ohida, T., Osaki, Y., Kobayashi, Y., Sekiyama, M., Minowa, M. (1999). Smoking prevalence of female nurses in the national hospitals of Japan. Tobacco Control, 8, 192-195. https://doi.org/10.1136/tc.8.2.192

Okeke, P. I., Ross, A., Esterhuizen, T., \& Van Wyk, J. (2012). Tobacco and alcohol use among healthcare workers in three public hospitals in KwaZulu-Natal, South Africa. South African Journal of Family Practice, 54(1), 61-67. https://doi.org/10.1080/20786204.2012.10874177

Owolabi, E. O., Goon, D. T., Adeniyi, O. V. \& Seekoe, E. (2017d). Adult binge drinking: rate, frequency and intensity in Buffalo City Metropolitan Municipality, South Africa. South African Journal of Family Practice, 4(1), 1-7. https://doi.org/10.1080/20786190.2017.1382970

Owolabi, E. O., Goon, D. T., Adeniyi, O. V., \& Seekoe, E. (2016). Correlates of pre-diabetes and Type 2 diabetes in buffalo city municipality, South Africa. Africa. Journal of Physical Activity and Health Sciences, 22, 1019-1035. https://doi.org/10.1136/bmjopen-2016- 014349

Owolabi, E. O., Goon, D. T., Adeniyi, O. V., \& Seekoe, E. (2017b). Social epidemiology of hypertension in Buffalo City Metropolitan Municipality (BCMM): cross-sectional study of determinants of prevalence, awareness, treatment and control among South African adults. BMJ Open, 2017b, 7, e014349. https://doi.org/10.1136/bmjopen-2016-014349

Owolabi, E. O., Goon, D. T., Adeniyi, O. V., Adedokun, A. O., \& Seekoe, E. (2017a). Prevalence and Associated Factors of Obesity among South African Adults: A Cross- Sectional Study. Online Journal of Health Allied Sciences, 16(2), 1.

Owolabi, E.O., Goon, D.T., Adeniyi, O.V., Adedokun, A.O., Seekoe, E. (2017c). Prevalence and factors associated with tobacco use among adults attending selected healthcare facilities in Buffalo City Metropolitan Municipality, South Africa. South African Family Practice, 59(6), 201-207. https://doi.org/10.1080/20786190.2017.134025. doi:10.1080/20786190.2017.1340251

Peer, N., Steyn, K., Lombard, C., Gwebushe, N., \& Levitt, N. (2013). A high burden of hypertension in the urban black population of Cape Town: the cardiovascular risk in Black South Africans (CRIBSA) study. PLoS One, 8, e78567. https://doi.org/10.1371/journal.pone.0078567

Phiri, L.P., Draper, C. E., Lambert, E. V., \& Kolbe-Alexander, T. L. (2014). Nurses' lifestyle behaviours, health priorities and barriers to living a healthy lifestyle: a qualitative descriptive study. BMC Nursing, 13, 38 . https://doi.org/10.1186/s12912-014-0038-6

Reddy, S. P., James, S., Sewpaul, R., Sifunda, S., Ellahebokus, A., \& Kambaran, N. S. (2010). Umthente Uhlaba Usamila - the South African Youth Risk Behaviour Survey 2008. Cape Town: Medical Research Council. 2010. https://doi.org/10.4314/asp.v6i1.31653

Sarna, L., Bialous, S.A., Sinha, K., Yang, Q., Wewers, M.E. (2010). Are health care providers still smoking? Data from the 2003 and 2006/2007 Tobacco Use Supplement-Current Population Surveys. Nicotine Tobacco 
Research, 12(11), 1167- 71. https://doi.org/10.1093/ntr/ntq161

Sejr, H., \& Osler, M. (2002). Do smoking and health education influence student Nurses' knowledge, attitudes and professional behaviour? Preventive Medicine, 34(2), 260-5. https://doi.org/10.1006/pmed.2001.0981

Sezer, H., Guler, N., \& Sezer, R.E. (2007). Smoking among Nurses in Turkey: Comparison with Other Countries. Journal of Health, Population, and Nutrition, 25(1), 107-111. https://doi.org/10.1136/tc.7.3.326a

Skaal, L., \& Pengpid, S. (2011). Obesity and health problems among South African healthcare workers: do healthcare workers take care of themselves? South African Journal of Family Practice, 53, 563-567. https://doi.org/10.1080/20786204.2011.10874153

Statistics South Africa. (2011). South African Statistics. South Africa, 2011, 1-190. Retrieved from http://www.statssa.gov.za/publications/SAStatistics/SAStatistics2011.pdf.

Trost, S. G., Owen, N., Bauman, A. E., Sallis, J. F., \& Brown, W. (2002). Correlates of adults' participation in physical activity: review and update. Medicine \& Science in Sports \& Exercise, 34(12), 1996-2001. https://doi.org/10.1097/00005768-200212000-00020

Van den Berg. V., Okeyo, A., Danhausser, A., \& Mariette, N. (2012). Body weight, eating practices and nutritional knowledge amongst university nursing students, Eastern Cape, South Africa. African Journal of Primary Health Care and Family Medicine, 4(1), 1-9. https://doi.org/10.4102/phcfm.v4i1.323

World Health Organization (2017). Global status report on non-communicable diseases 2010. Retrieved from: http://www.who.int/nmh/publications/ncd_report2010/en/.

Zhao, I., \& Turner, C. (2008). The impact of shift work on people's daily health habits and adverse health outcomes. Australian Journal of Advanced Nursing, 25, 8. https://doi.org/10.1111/inm.12164

Zhao, I., Bogossian, F., Song, S., \& Turner, C. (2011). The association between shift work and unhealthy weight: a cross-sectional analysis from the Nurses and Midwives' e- cohort Study. Journal of Occupational and Environmental Medicine, 53, 153-158. https://doi.org/10.1097/JOM.0b013e318205e1e8

\section{Copyrights}

Copyright for this article is retained by the author(s), with first publication rights granted to the journal.

This is an open-access article distributed under the terms and conditions of the Creative Commons Attribution license (http://creativecommons.org/licenses/by/4.0/). 